\section{Research Square \\ Preprints are preliminary reports that have not undergone peer review. They should not be considered conclusive, used to inform clinical practice, or referenced by the media as validated information.}

\title{
Tasks in Group Quarantine Centers in Relation to the Emotional Distress of Personnel the Experiences from COVID-19 Epidemic Prevention in Taiwan
}

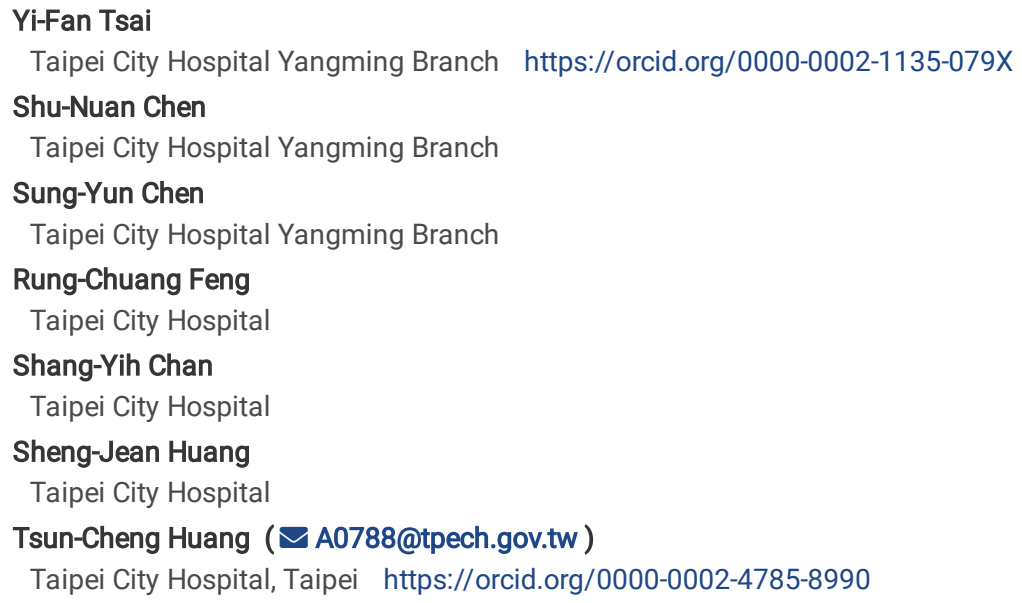

Research article

Keywords: COVID-19, epidemic , quarantine

Posted Date: December 1st, 2020

DOI: https://doi.org/10.21203/rs.3.rs-115172/v1

License: @) (1) This work is licensed under a Creative Commons Attribution 4.0 International License. Read Full License 


\section{Abstract}

Background: In order to prevent COVID-19, Taiwan Central Epidemic Command Center established group quarantine centers in January 2020 to implement isolation and epidemic prevention. The task groups in the group quarantine centers included the safety, logistics, and health groups. The objectives of this study were to understand whether the emotional distresses of group quarantine centers personnel are disturbed under high-pressure work environment.

Methods: A structured questionnaire was designed. Its content contained two parts: the first part collected the demographical information of the participants, and the second part was a scale named the Brief Symptom Rating Scale (BSRS-5). The data collected were entered and analyzed using IBM SPSS Statistics for Windows, Version 21.0, and the difference analysis among the three groups were conducted in terms of the variables (significance level $p<0.05$ ); related factors affecting emotional scores on the BSRS-5 were identified through multiple regression analysis.

Results: The online questionnaires were filled out from August 6 to August 13,2020, and a total of 155 staffs were analyzed further. The safety group was collected 70 staffs (45.2\%), the health group was collected 57 staffs (36.8\%) and the logistics group was collected 28 staffs (18.0\%). According to the analysis we found that three important results. First, no positive cases of COVID-19 been screened, the personnel do not feel distressed on duty in group quarantine centers. Second, when a quarantine case is screened positive for COVID-19, it will increase staff's emotional distress in all three group and the odds ratio with a BSRS- 5 score greater than or equal to 6 points is 4.53 times $(\mathrm{OR}=4.53,95 \% \mathrm{Cl}: 1.83-11.21)$ of cases that have not been screened as positive. Final, Cases screened as positive did not cause emotional problems in retired personnel serving in group quarantine centers.

Conclusion: In the face of COVID-19 disease, our government should not only take care of people in the community, but also protect and take care of the front-line epidemic prevention personnel. Our government should be understand the emotional distresses of personnel and provide counseling and care, so that personnel can continue to protect people of Taiwan during epidemic prevention.

\section{Background}

In December 2019, a new infectious primary atypical pneumonia broke out in Wuhan, China. On January 30, 2020, the World Health Organization (WHO) declared the outbreak of the novel coronavirus a Public Health Emergency of International Concern [1, 2]. On February 11, the WHO officially named the disease that people develop after becoming infected with the virus "coronavirus disease 2019" (COVID-19) [3]. On January 2, 2020, the response team of Taiwan CDC was set up to respond to the mystery pneumonia epidemic in Wuhan, China. On January 20, 2020, level 3 of the Central Epidemic Command Center (CECC) was established to integrate resources of the administration, the academic, medical, and private sectors to fight against COVID-19. To preserve Taiwan's limited acute medical resources for diagnosed patients in the greatest need-separating quarantine from acute medical treatment and preventing the expansion of community spread-group quarantine centers were established in Taiwan at the end of January 2020 . Distributed in 12 counties and cities, these centers possessed a total treatment capacity of 2126 rooms as of May 18 [4-6]. People eligible to be quarantined in the centers were divided into five types: (1) travelers subject to mandatory group quarantine after entering the country; (2) people who had been in frequent contact with diagnosed cases of COVID-19 as well as people who did not follow related regulations during home isolation; (3) individuals who entered Taiwan from regions with outbreaks* and did not adhere to related regulations during home quarantine; (4) individuals for whom no home isolation or home quarantine site was available after coordination by local governments (*the definition of "regions with outbreaks" adhered to the latest announcement by the Taiwan Centers for Disease Control); and (5) people who had been approved by the CECC for severe pneumonia with novel pathogens, namely workers and personnel of agencies (institutions) authorized by the CECC, including medical, long-term care, and correction institutions [7].

The task groups in the group quarantine centers included the safety, logistics, and health groups. The CECC was in charge of the overall organization, while the health group leader in each quarantine center acted as the commander who reported news about the center to the CECC. The main tasks in each group are explained as follows: the commander of each site arranged and adjusted the work of each task group according to the actual on-site situation. "The safety group" included policemen and chauffeurs. In terms of manpower allocation, at least one policeman and one chauffeur were assigned to each gate for each shift. They were in charge of traffic arrangements to designated quarantine locations for quarantined individuals of the first type; the security of quarantined individuals travelling from or to quarantine locations; baggage security checks before quarantined individuals checked in; checking of materials sent by families or friends to ensure no dangerous objects; personnel security during quarantine; control of access to designated quarantine sites; safety management of quarantine areas; picking up of people for quarantine; and baggage delivery assistance. "The logistics group" included logistics administrators and cleaners. Regarding manpower allocation, a minimum of one administrator and two cleaners were assigned for each shift. They were in charge of helping quarantined individuals check in and out; providing quarantined individuals with food and accommodation and personnel with food; providing basic daily necessities, materials for personal pandemic prevention, and body temperature measurement equipment; performing environmental hygiene maintenance as well as cleaning and disinfection; safekeeping belongings of quarantined individuals; and arranging the signing in and out of personnel. "The health group" included doctors, nurses, infection control personnel, and medical administrators. In terms of manpower allocation, at least one doctor, one infection control employee, and one member of nursing staff (one for every 30 quarantined individuals) were assigned for each shift. They were in charge of issuing the "Notice of Group Quarantine and Right to Petition for Habeas Corpus Relief (Coronavirus disease 2019, COVID-19)" and "Notice of Abolishment/Repeal of Group Quarantine (Coronavirus disease 2019, COVID-19)"; designating quarantine locations; arranging rooms and listings for quarantined persons; performing daily tracking as well as synthesizing and reporting quarantined individuals' health situation; assisting in medical treatment for quarantined individuals with symptoms; collecting specimens regarding the first type of subjects; and providing mental health counseling for quarantined individuals and related personnel [7].

Regarding the sourcing of group quarantine center personnel, the CECC requested the quarantine centers to be responsible for recruitment. The leaders of the centers first contacted people by telephone or disseminated questionnaires to seek personnel. People who agreed then filled in their information, which was sent to the Ministry of Health and Welfare (MHW). The MHW then sent recruitment letters to them. Once recruited, they were required, before serving in 
the quarantine centers, to complete 8 hours of educational training in the form of the following courses: (1) introduction to COVID-19; (2) training on the wearing and removal of protective clothing of all levels, as well as reporting exercises and demonstrations; (3) introduction to the flow of a quarantine center, as well as emergency evacuation and fire safety; (4) introduction to the standard operating procedures of environmental cleaning and disinfection (courses 1-4 lasted 1 hour each); (5) the standard operating procedures of group quarantine centers; (6) abnormal event simulation exercises and procedures (e.g., fire, how to deal with positive cases) along with rolling correction at all times (courses 5 and 6 each lasted 2 hours). The commanders, deputy commanders, and group leaders of the quarantine centers created LINE contact groups with central government officials at all levels; the leader of each group sent messages regarding the implementation of necessary pandemic communication and coordination to personnel, informing them about the latest policies to follow and continuing with the rolling correction. Details of the group operating procedures for quarantine centers are presented in Fig. 1 [7].

According to relevant literature, numerous frontline medical personnel have undergone extreme emotional stress and exhibited symptoms of fatigue, psychological trauma, anxiety, and depression during outbreaks of infectious diseases, such as severe acute respiratory syndrome (SARS) and Ebola virus disease [8-10]. Moreover, a study indicated that medical personnel caring for patients in the acute phase of SARS infection were more susceptible to severe psychological distress [11]. Currently, too many uncertainties and effects exist related to the outbreak of the COVID-19 pandemic, which not only lead to physical and physiological problems but could result in psychological stress and emotional problems. Moreover, personnel working in group quarantine centers in Taiwan were in contact with quarantined individuals returning to Taiwan from around the globe. Emotional stress and distress were likely to arise in personnel from the uncertainty of whether the quarantined individuals they were in contact with would be diagnosed with COVID-19. This study aimed to understand whether the psychological conditions of quarantine center personnel were altered by high stress and exposure to an uncertain working environment. The analysis results can serve as a reference for improving the mental health of quarantine center personnel facing infectious diseases and formulating related prevention and supporting measures.

\section{Methods Sample}

We recruited volunteers to participate in this study. They were required to meet the following three criteria: worked in a group quarantine center in Taiwan; consented to participate in the research; and were adults aged 20 years or older.

\section{Data collection}

A structured questionnaire was designed. Its content contained two parts: the first part collected the demographical information of the participants, and the second part was a scale named the Brief Symptom Rating Scale (BSRS-5, also known as the "mood thermometer") compiled by Professor Ming-Been Lee [12]. In this study, Professor Lee granted authorization to use the scale. The BSRS-5 is a screening tool for examining mental health needs and aims to rapidly understand an individual's psychological care needs, enabling suitable mental health services to be provided. Its internal consistency reliability (Cronbach alpha) was $0.77-0.90$ and its retest reliability was 0.82 . The scale comprises five items: trouble falling asleep (to measure insomnia), feeling tense or highly strung (to measure anxiety), feeling irritable or angry (to measure anger), feeling down and depressed (to measure depression), and feeling inferior to others (to measure low self-esteem). Total scores of the aforementioned five items below 6 pertain to the normal range, signifying good physical and mental adaptability. Total scores ranging from 6 to 9 pertain to mild emotional distress; thus, stress management and emotional relief are recommended. Total scores ranging from 10 to 14 pertain to moderate emotional distress; professional consultation is recommended, and the person is advised to seek a psychological consultation or receive a professional consultation. Total scores above 15 pertain to extreme emotional distress; great care is required, and the person is advised to seek professional counseling or psychiatric treatment [12]. A sixth item was added regarding suicidal thoughts, which was scored separately; professional counseling or psychiatric treatment were suggested when the score for this item was above 2 (a moderate level).

The symptom rating scale designed by this study for group quarantine centers covered a total of three time points: (1) before taking part in tasks in quarantine centers; (2) without cases screened as positive for COVID-19 in quarantine centers; and (3) with cases screened as positive for COVID-19 in quarantine centers. The content of the BSRS-5 was adopted. A structured questionnaire was constructed using SurveyCake, a free Internet cloud questionnaire service. The principal investigator sent messages along with the questionnaire link and QR code to the coordinators of the quarantine centers. A clickable button was set in the online questionnaire survey for the subjects to click "Agree." Only those who clicked "Agree" could fill in the questionnaire survey. In addition, a network security mechanism was established to ensure the study content would not be altered by hackers or other personnel.

We using the $\mathrm{G} *$ Power 3 that is a flexible statistical power analysis program, to select $T$ test, the effect size is set to 0.3 , the significance level is 0.05 , and the verification power $(1-\beta)$ is 0.90 , and taking into account the loss of network samples and the incomplete answer, it is $20 \%$. This study expects to recruit more than 120 subjects for questionnaire survey.

\section{Data analysis}

This study coded, input, and reviewed the valid returned questionnaires. The research data were analyzed using IBM Corp. Released 2012. IBM SPSS Statistics for Windows, Version 21.0. Armonk, NY: IBM Corp. and statistical analyses were conducted according to the objectives of the study and the content of the questionnaire. The analysis methods involved presenting the demographical information through descriptive statistics in terms of mean and standard deviation. Regarding the valid questionnaires, the difference analysis among the three groups (the safety, health, and logistics groups) were conducted in terms of the variables (significance level $p<0.05$ ); related factors affecting the emotional scores on the BSRS- 5 were identified through multiple regression analysis.

\section{Results}




\section{Sample characteristics}

The online questionnaires were filled out during August 6-13, 2020. Questionnaires were received from a total of 155 participants; Table 1 presents the descriptive analysis of their demographical characteristics. The respondents were divided into three groups according to their jobs in group quarantine centers. There were 70 cases from the safety group, including 64 men accounting for the majority (91.4\%) and six women (8.6\%). The average age of the group was $41.4 \pm 9.6$ years; the average job tenure was $19.7 \pm 10.8$ years. There were 57 cases from the health group, including 51 women accounting for the majority (89.5\%) and six men (10.5\%). The average age of the group was $49.4 \pm 8.6$ years; those aged between $51-60$ years comprised the majority, accounting for $42.1 \%$; the average job tenure was $24.2 \pm 8.3$ years. There were 28 cases from the logistics group, including 18 men accounting for majority (64.3\%) and 10 women (35.7\%). The average age of the group was $42.8 \pm 11.4$ years; the average job tenure was $14.4 \pm 11.4$ years.

Table 1

Descriptive data on characteristics in our samples $(n=155)$

\begin{tabular}{|c|c|c|c|c|}
\hline \multicolumn{2}{|l|}{ Characteristics } & \multirow{2}{*}{$\begin{array}{l}\text { safety group } \\
(n=70)(\%) \\
64(91.4)\end{array}$} & \multirow{2}{*}{$\begin{array}{l}\text { health group } \\
(n=57)(\%) \\
6(10.5)\end{array}$} & \multirow{2}{*}{$\begin{array}{l}\text { logistics group } \\
(n=28)(\%) \\
18(64.3)\end{array}$} \\
\hline Gender & Male & & & \\
\hline & Female & $6(8.6)$ & $51(89.5)$ & $10(35.7)$ \\
\hline \multirow[t]{5}{*}{ Age-group } & $21-30$ & $17(24.3)$ & $3(5.3)$ & $4(14.3)$ \\
\hline & $31-40$ & $6(8.6)$ & $4(7.0)$ & $10(35.7)$ \\
\hline & $41-50$ & $41(58.5)$ & $22(38.6)$ & $5(17.9)$ \\
\hline & $51-60$ & $6(8.6)$ & $24(42.1)$ & $7(25.0)$ \\
\hline & $61-69$ & 0 & $4(7.0)$ & $2(7.1)$ \\
\hline Average age (years) & & $41.4 \pm 9.6$ & $49.4 \pm 8.6$ & $42.8 \pm 11.4$ \\
\hline \multirow[t]{5}{*}{ Education } & Junior high school & 0 & 0 & 1(3.6) \\
\hline & Senior High school & $7(10.0)$ & $2(3.5)$ & $2(7.1)$ \\
\hline & College & $35(50.0)$ & $10(17.5)$ & $2(7.1)$ \\
\hline & University & $28(40.0)$ & $30(52.6)$ & $18(64.3)$ \\
\hline & Graduate school & 0 & $15(26.4)$ & $5(17.9)$ \\
\hline \multirow[t]{2}{*}{ Marriage } & Single & 25(35.7) & $10(17.5)$ & $8(28.6)$ \\
\hline & Married & $45(64.3)$ & $47(82.5)$ & $20(71.4)$ \\
\hline \multirow[t]{5}{*}{ Job tenure } & Less than $10 \mathrm{yr}(\mathrm{s})$ & $20(28.6)$ & $6(10.5)$ & $14(50.0)$ \\
\hline & 11 20yr(s) & $5(7.1)$ & $12(21.1)$ & $6(21.4)$ \\
\hline & 21 30yr(s) & $38(54.3)$ & $28(49.1)$ & $5(17.6)$ \\
\hline & $31 \sim 40 \mathrm{yr}(\mathrm{s})$ & $7(10.0)$ & $10(17.5)$ & $3(11.0)$ \\
\hline & More than $40 \mathrm{yr}(\mathrm{s})$ & 0 & $1(1.8)$ & 0 \\
\hline Average job tenure (years) & & $19.7 \pm 10.8$ & $24.2 \pm 8.3$ & $14.4 \pm 11.4$ \\
\hline \multirow[t]{2}{*}{ cases screened positive for coronavirus } & Yes & $34(48.6)$ & $37(64.9)$ & $10(35.7)$ \\
\hline & No & $36(51.4)$ & $20(35.1)$ & $18(64.3)$ \\
\hline
\end{tabular}

\section{Analysis of changes in emotional score on the BSRS-5 of group quarantine centers personnel}

\section{Before participating in tasks in quarantine centers}

According to the questionnaire content, robust analysis of variance (ANOVA) and Games-Howell tests were adopted for testing because of the heterogeneity of variance before participation in tasks in group quarantine centers. According to a one-way ANOVA on the changes in the emotional score of each group, the total BSRS- 5 score of safety group personnel was $2.10 \pm 2.61$, that of health group personnel was $2.11 \pm 1.86$, and that of logistics group personnel was $1.71 \pm 1.86$; no statistical difference was observed $(p=0.630)$. Average scores for the item on having suicidal thoughts were all below 2 , indicating the absence of obvious emotional distress in the participating personnel of the three groups before they participated in tasks in quarantine centers (see in Table 2). 
Table 2

One-way analysis of variance on changes in the emotional score of each group.

\begin{tabular}{|c|c|c|c|c|}
\hline \multicolumn{2}{|l|}{ Characteristics } & \multirow{2}{*}{$\begin{array}{l}\text { safety group } \\
(n=70)(\%) \\
64(91.4)\end{array}$} & \multirow{2}{*}{$\begin{array}{l}\text { health group } \\
(n=57)(\%) \\
6(10.5)\end{array}$} & \multirow{2}{*}{$\begin{array}{l}\text { logistics group } \\
(n=28)(\%) \\
18(64.3)\end{array}$} \\
\hline Gender & Male & & & \\
\hline & Female & $6(8.6)$ & $51(89.5)$ & $10(35.7)$ \\
\hline \multirow[t]{5}{*}{ Age-group } & $21-30$ & $17(24.3)$ & $3(5.3)$ & $4(14.3)$ \\
\hline & $31-40$ & $6(8.6)$ & $4(7.0)$ & $10(35.7)$ \\
\hline & $41-50$ & $41(58.5)$ & $22(38.6)$ & $5(17.9)$ \\
\hline & $51-60$ & $6(8.6)$ & $24(42.1)$ & $7(25.0)$ \\
\hline & $61-69$ & 0 & $4(7.0)$ & $2(7.1)$ \\
\hline Average age (years) & & $41.4 \pm 9.6$ & $49.4 \pm 8.6$ & $42.8 \pm 11.4$ \\
\hline \multirow[t]{5}{*}{ Education } & Junior high school & 0 & 0 & $1(3.6)$ \\
\hline & Senior High school & $7(10.0)$ & $2(3.5)$ & $2(7.1)$ \\
\hline & College & $35(50.0)$ & $10(17.5)$ & $2(7.1)$ \\
\hline & University & $28(40.0)$ & $30(52.6)$ & $18(64.3)$ \\
\hline & Graduate school & 0 & $15(26.4)$ & $5(17.9)$ \\
\hline \multirow[t]{2}{*}{ Marriage } & Single & $25(35.7)$ & $10(17.5)$ & $8(28.6)$ \\
\hline & Married & $45(64.3)$ & $47(82.5)$ & $20(71.4)$ \\
\hline \multirow[t]{5}{*}{ Job tenure } & Less than 10 year(s) & $20(28.6)$ & $6(10.5)$ & $14(50.0)$ \\
\hline & $11 \sim 20$ year(s) & $5(7.1)$ & 12(21.1) & $6(21.4)$ \\
\hline & $21 \sim 30$ year(s) & $38(54.3)$ & $28(49.1)$ & $5(17.6)$ \\
\hline & $31 \sim 40$ year(s) & $7(10.0)$ & $10(17.5)$ & $3(11.0)$ \\
\hline & More than 40 year(s) & 0 & $1(1.8)$ & 0 \\
\hline Average job tenure (years) & & $19.7 \pm 10.8$ & $24.2 \pm 8.3$ & $14.4 \pm 11.4$ \\
\hline \multirow[t]{2}{*}{ cases screened positive for coronavirus } & Yes & $34(48.6)$ & $37(64.9)$ & $10(35.7)$ \\
\hline & No & $36(51.4)$ & $20(35.1)$ & $18(64.3)$ \\
\hline
\end{tabular}

\section{Without cases screened as positive for COVID-19 in quarantine centers}

To analyze the questionnaire content regarding the personnel of the three groups when participating in tasks in quarantine centers, a nonparametric MannWhitney U test was employed to compare before/after cases screened as positive for COVID-19 before/after participating; no statistical difference was found among the BSRS-5 emotional scores of the three groups, as shown in Table 3.

Table 3

Statistics of changes in BSRS- 5 emotional scores without cases screened as positive for COVID-19 $(n=74)$

\begin{tabular}{|llllll|}
\hline BSRS-5 & & $\begin{array}{l}\text { safety group } \\
(\mathbf{n}=\mathbf{7 0})\end{array}$ & health group $(\mathbf{n = 5 7 )}$ & $\begin{array}{c}\text { logistics group } \\
(\mathbf{n = 2 8})\end{array}$ & $p$ value \\
\hline Before & Insomnia & $0.57 \pm 0.73$ & $0.65 \pm 0.61$ & $0.46 \pm 0.64$ & 0.444 \\
\cline { 2 - 6 } the task & Anxiety & $0.41 \pm 0.60$ & $0.58 \pm 0.63$ & $0.43 \pm 0.57$ & 0.300 \\
\cline { 2 - 6 } & Angry & $0.41 \pm 0.58$ & $0.40 \pm 0.53$ & $0.32 \pm 0.48$ & 0.693 \\
\cline { 2 - 6 } & Depression & $0.40 \pm 0.57$ & $0.30 \pm 0.60$ & $0.25 \pm 0.44$ & 0.355 \\
\hline & Low self-esteem & $0.30 \pm 0.55$ & $0.18 \pm 0.38$ & $0.25 \pm 0.44$ & 0.318 \\
\cline { 2 - 6 } & Total score average & $2.10 \pm 2.61$ & $2.11 \pm 1.86$ & $1.71 \pm 1.86$ & 0.630 \\
\cline { 2 - 6 } & Suicide ideation & $0.01 \pm 0.12$ & $0.02 \pm 0.13$ & $0.04 \pm 0.19$ & 0.858 \\
\hline
\end{tabular}




\section{With cases screened as positive for COVID-19 in quarantine centers}

A nonparametric Mann-Whitney U test was used to compare before/after cases screened as positive for COVID-19 before/after participating, revealing that during participation in tasks in the centers with cases screened as positive, the BSRS- 5 emotional scores of 34 participants in the safety group and 10 in the logistics group were all significantly higher than those before participating in tasks. Regarding the safety group, a significant difference was observed in comparisons of measured insomnia, anxiety, anger, depression, and low self-esteem, and the total score increased from the original average ( $3.41 \pm 3.10)$ to an average of $6.09 \pm 4.99(p<0.000)$, pertaining to mild emotional distress by estimation. Moreover, scores for the item on having suicidal thoughts in the safety group increased from an average of 0 to an average of $0.12 \pm 0.33(p=0.046)$, indicating a significant increase despite being lower than 2 . Regarding the logistics group, the total BSRS- 5 scores increased from the original average of $1.70 \pm 2.16$ to an average of $2.40 \pm 2.46(p=0.034)$. As for the health group, the total BSRS- 5 emotional scores of 37 participants in contact with positive cases were $3.08 \pm 2.58$, which did not reach statistical significance despite being higher than the scores before participating in tasks in quarantine centers (2.51 \pm 1.88$)$, as shown in Table 4.

Table 4

Statistics of Changes in the Emotional Score of BSRS- 5 with Cases Screened as Positive for COVID-19 $(n=81)$

\begin{tabular}{|c|c|c|c|}
\hline BSRS-5 & No positive cases detected & $\begin{array}{l}\text { Screen } \\
\text { positive cas }\end{array}$ & $p$ value \\
\hline \multicolumn{4}{|l|}{ Safety group $(n=34)$} \\
\hline Insomnia & $0.59 \pm 0.78$ & $1.56 \pm 1.13$ & $0.001^{* *}$ \\
\hline Anxiety & $0.47 \pm 0.66$ & $1.56 \pm 1.16$ & $<0.001^{* *}$ \\
\hline Angry & $0.47 \pm 0.66$ & $1.24 \pm 1.21$ & $0.001^{* *}$ \\
\hline Depression & $0.41 \pm 0.66$ & $1.06 \pm 1.20$ & $0.004^{* *}$ \\
\hline Low self-esteem & $0.38 \pm 0.55$ & $0.68 \pm 0.73$ & $0.046^{*}$ \\
\hline Total score average & $3.41 \pm 3.10$ & $6.09 \pm 4.99$ & $<0.001^{* *}$ \\
\hline Suicide ideation & $0.00 \pm 0.00$ & $0.12 \pm 0.33$ & $0.046^{*}$ \\
\hline \multicolumn{4}{|l|}{ Health group $(n=37)$} \\
\hline Insomnia & $0.68 \pm 0.58$ & $0.89 \pm 0.66$ & 0.090 \\
\hline Anxiety & $0.70 \pm 0.52$ & $0.95 \pm 0.74$ & 0.087 \\
\hline Angry & $0.51 \pm 0.56$ & $0.54 \pm 0.69$ & 1.000 \\
\hline Depression & $0.41 \pm 0.69$ & $0.49 \pm 0.73$ & 0.439 \\
\hline Low self-esteem & $0.22 \pm 0.42$ & $0.22 \pm 0.48$ & 1.000 \\
\hline Total score average & $2.51 \pm 1.88$ & $3.08 \pm 2.58$ & 0.219 \\
\hline Suicide ideation & $0.00 \pm 0.00$ & $0.03 \pm 0.16$ & 0.317 \\
\hline \multicolumn{4}{|l|}{ Logistics group $(\mathrm{n}=10)$} \\
\hline Insomnia & $0.40 \pm 0.70$ & $0.50 \pm 0.71$ & 0.317 \\
\hline Anxiety & $0.40 \pm 0.52$ & $0.70 \pm 0.67$ & 0.083 \\
\hline Angry & $0.30 \pm 0.48$ & $0.40 \pm 0.52$ & 0.317 \\
\hline Depression & $0.30 \pm 0.48$ & $0.50 \pm 0.53$ & 0.157 \\
\hline Low self-esteem & $0.30 \pm 0.48$ & $0.30 \pm 0.48$ & 1.000 \\
\hline Total score average & $1.70 \pm 2.16$ & $2.40 \pm 2.46$ & $0.034^{*}$ \\
\hline Suicide ideation & $0.10 \pm 0.32$ & $0.10 \pm 0.32$ & 1.000 \\
\hline
\end{tabular}

A chi-square test and risk assessment analysis were conducted on those with a BSRS- 5 score equal to or greater than 6 and whether there were cases screened as positive for COVID-19. The results revealed the odds of the BSRS- 5 score with cases screened as positive were 4.53 times those of the BSRS-5 score without cases screened as positive ( $\mathrm{OR}=4.53,95 \% \mathrm{Cl}: 1.83-11.21)$, indicating the susceptibility of the emotional score (see in Table 5). 
Table 5

Chi-Square Tests and Risk Estimates on BSRS-5 Scores and Whether There Were Cases Screened as Positive for COVID-19

\begin{tabular}{|c|c|c|c|c|c|c|c|}
\hline & & BSR & $5 \mathrm{sco}$ & & & Risk estimat & \\
\hline & & $<6$ & $\geq 6$ & Total & Fisher's & Odds Ratio & 95\% Confidence interval \\
\hline & & & & & Exact test & & \\
\hline & & & & & (2-sides) p value & & \\
\hline Screen & No & 67 & 7 & 74 & $<0.000^{* *}$ & 4.53 & $1.83-11.21$ \\
\hline positive cases & YES & 55 & 26 & 81 & & & \\
\hline Total & & 122 & 33 & 155 & & & \\
\hline
\end{tabular}

\section{Analysis on variables associated with changes in emotional scores}

\section{Statistics of changes in the emotional scores of retired and in-service personnel}

In terms of the questionnaire content analysis, among respondents who participated in tasks in centers, 21 (13.5\%) were retired; their average age was $60.0 \pm 3.0$ years; all were married; those who held a bachelor's degree or higher accounted for $76.2 \%$; and their average job tenure was $31.9 \pm 4.7$ years; those from the health group comprised the majority (15 participants accounting for $71.4 \%$ ); one was from the safety group (accounting for $4.8 \%$ ); and five were from the logistics group (23.8\%). Analysis indicated that the BSRS-5 emotional scores of retired personnel were not affected by being in contact with patients who were positively diagnosed with COVID-19 during health care (see in Table 6).

Table 6

Statistics of Changes in BSRS-5 Emotional Scores of Retired Personnel $(n=21)$

\begin{tabular}{|lllll|}
\hline BSRS-5 & $\begin{array}{l}\text { Before } \\
\text { the task }\end{array}$ & No positive cases detected & $\begin{array}{l}\text { Screen } \\
\text { positive cases }\end{array}$ & $p$ value \\
\hline Insomnia & $0.57 \pm 0.68$ & $0.62 \pm 0.74$ & $0.75 \pm 0.93$ & 0.917 \\
\hline Anxiety & $0.33 \pm 0.58$ & $1.53 \pm 0.38$ & $0.63 \pm 0.89$ & 0.541 \\
\hline Angry & $0.19 \pm 0.40$ & $0.43 \pm 0.51$ & $0.44 \pm 0.81$ & 0.531 \\
\hline Depression & $0.10 \pm 0.30$ & $0.29 \pm 0.46$ & $0.38 \pm 0.62$ & 0.198 \\
\hline Low self-esteem & $0.38 \pm 2.65$ & $0.10 \pm 0.30$ & $0.06 \pm 0.25$ & 0.925 \\
\hline Total score average & $1.29 \pm 1.55$ & $1.76 \pm 1.87$ & $1.61 \pm 2.87$ & 0.488 \\
\hline Suicide ideation & $0.00 \pm 0.00$ & $0.00 \pm 0.00$ & $0.00 \pm 0.00$ & 1.000 \\
\hline
\end{tabular}

\section{Multiple linear regression for examining the variables}

An examination of the relationships among the variables through multiple linear regression analysis revealed that the total BSRS- 5 scores of the personnel of the three groups before participating in tasks and without cases screened as positive for COVID-19 were not significantly affected by age, gender, education, job tenure, marital status, or occupation (retired or not). However, their total BSRS-5 scores were significantly affected when there were positive cases of COVID-19 diagnosed among the patients in the quarantine centers. Research and analysis revealed that the existence of cases screened as positive did affect the mood of the personnel of the three groups (see in Table 7). 
Table 7

Total BSRS-5 Scores with Cases Screened as Positive and Multiple Linear Regression Analysis
\begin{tabular}{|lllll|}
\hline BSRS-5 & $\begin{array}{l}\text { Before } \\
\text { the task }\end{array}$ & No positive cases detected & $\begin{array}{l}\text { Screen } \\
\text { positive cases }\end{array}$ & p value \\
\hline Insomnia & $0.57 \pm 0.68$ & $0.62 \pm 0.74$ & $0.75 \pm 0.93$ & 0.917 \\
\hline Anxiety & $0.33 \pm 0.58$ & $1.53 \pm 0.38$ & $0.63 \pm 0.89$ & 0.541 \\
\hline Angry & $0.19 \pm 0.40$ & $0.43 \pm 0.51$ & $0.44 \pm 0.81$ & 0.531 \\
\hline Depression & $0.10 \pm 0.30$ & $0.29 \pm 0.46$ & $0.38 \pm 0.62$ & 0.198 \\
\hline Low self-esteem & $0.38 \pm 2.65$ & $0.10 \pm 0.30$ & $0.06 \pm 0.25$ & 0.925 \\
\hline Total score average & $1.29 \pm 1.55$ & $1.76 \pm 1.87$ & $1.61 \pm 2.87$ & 0.488 \\
\hline Suicide ideation & $0.00 \pm 0.00$ & $0.00 \pm 0.00$ & $0.00 \pm 0.00$ & 1.000 \\
\hline ( $\mathrm{n}=81$ ) & & & & \\
\hline
\end{tabular}

\section{Discussion}

After summarizing the statistical analysis results for the online questionnaires, the following three conclusions were derived.

\section{No emotional problems in the personnel before or after serving (without cases screened as positive)}

The results indicated that the personnel of the three groups did not have emotional problems before participating in tasks in group quarantine centers or after (without cases screened as positive). Such results attested to the fact that immediately after group quarantine centers were established in Taiwan at the end of January 2020, experts on epidemic prevention built a complete standard operating procedure as well as branched flows of anti-pandemic quarantine, which along with the rolling correction of anti-pandemic policy at all times ensured the effectiveness of epidemic prevention was clear to the world. Safe and reassuring quarantine environments with ample manpower allowed the personnel to work at ease. Moreover, the participating personnel all received 8 hours of educational training before participation, including in technical exercises, to ensure the personnel understood and were familiar with the anti-pandemic work at hand. Thus, no emotional problems emerged in the personnel in the three groups after serving in the quarantine centers.

Noteworthily, however, mild suicidal thoughts emerged in some personnel in all three groups before they served in quarantine centers. Whether these personnel already experienced emotional distress in their daily life or work requires further examination, and timely care and counseling interventions are required. In the future, the collected data will be reported to group quarantine centers in Taiwan to facilitate early and timely care and prevention intervention and avoid regrets in the future.

\section{Emotional problems in personnel increased as cases screened positive for COVID-19}

According to the analysis and research results, when cases were screened as positive for COVID-19, the odds of BSRS- 5 scores being above 6 (mild emotional distress) were 4.53 times those without positive cases $(\mathrm{OR}=4.53,95 \% \mathrm{Cl}$ : $1.83-11.21)$; the emotional scores of the personnel of the three groups all significantly increased (those in the health group increased without reaching the statistical significance). In addition, COVID-19 has been proven to be infectious through human-to-human transmission and have high incidence and potential fatality. All these factors caused the personnel to worry about their own safety and body protection when looking after confirmed cases despite their awareness of wearing protective equipment $[13,14]$.

Among the personnel of the three groups, the BSRS- 5 items regarding personnel in the safety group with cases screened as positive were especially noteworthy. The average score for measured insomnia increased by $0.62-1.32(p=0.001)$; that for measured anxiety increased by $0.03-1.59$ ( $p<0.001)$; that for measured anger increased by $0.40-1.32(p=0.001)$; that for measured depression increased by $0.11-1.19(p=0.004)$; and that for measured low self-esteem increased by $0.12-0.48(p=0.046)$. The average BSRS- 5 score of the safety group increased from $3.41 \pm 3.10$ to $6.09 \pm 4.99$, reaching the level of mild emotional distress $(p<0.001)$. Through analysis, a reason was found to be that one of the tasks of the personnel of the "safety group" in the centers was conducting baggage security checks before quarantined individuals checked in. These personnel often had to touch the baggage of the quarantined individuals. When informed of in-center cases screened as positive, these personnel would worry whether they had been infected from touching the baggage of those patients. Moreover, the safety group was entirely in charge of personnel safety, control of access to the quarantine centers, and safety management tasks in the quarantine areas, assuming relatively heavy responsibility. All the aforementioned factors led more easily to mild emotional distress as exhibited through the BSRS-5 of the safety group compared with other groups. This study suggests that in the future, the government should implement more detailed procedure planning and support measures regarding baggage security checks before quarantined individuals check in; furthermore, it should consider allocating more manpower to the quarantine centers for assistance to alleviate the personnel's worries and doubts and reduce their emotional problems.

Cases screened as positive did not cause emotional problems in retired personnel serving in group quarantine centers 
Among the online questionnaires received from retired personnel, those from personnel in the health group accounted for the majority (71.4\%). Analysis indicated that the inherent sense of mission in these specialized professional medical personnel made them rather passionate about and attracted to being able to contribute to the general public through their skills and knowledge after retirement. Moreover, since most of the retired medical personnel had experienced the threat of SARS in Taiwan in 2003, they knew how to handle and cope with cases of infectious diseases, and were thus less stressed emotionally, which allowed them to provide diverse assistance to quarantined individuals while having no emotional problems.

\section{Conclusion}

This study conducted an online questionnaire survey on the emotional problems of personnel in group quarantine centers through the authorized use of BSRS-5. Through this study, the psychological care needs of the personnel were understood, and appropriate mental health services and a reference basis were further provided. The three groups represent the main personnel in direct or indirect charge of serving the quarantined individuals in group quarantine centers. Research indicated that the risk of infection for personnel in frequent contact with individuals positively diagnosed with COVID-19 was higher compared with others, and they were more likely to exhibit symptoms of emotional problems such as insomnia, tension, anxiety, melancholy, and pain [15]. Group quarantine centers in Taiwan not only provide isolated spaces for those eligible to be quarantined; they had two other major purposes: they preserve the limited acute medical resources in Taiwan for diagnosed patients genuinely in need to separate quarantine from acute medical treatment, and second, they act as anti-pandemic outposts for communities to avoid the expansion of community spread. Timely therapy and treatment through telemedicine is available for patients who encounter health problems. Thus, in facing the highly infectious COVID-19, the government should further protect and care for frontline anti-pandemic personnel in addition to looking after community residents. If the stress or psychological distress of on-site personnel is understood at all times, and supportive resources or counseling and care are provided to them according to their needs, the personnel will be able to continue to play the role of anti-pandemic gatekeepers with healthy bodies and minds, thereby protecting the health of Taiwan's citizens.

\section{Abbreviations}

COVID-19: Coronavirus disease 2019; WHO: World Health Organization; CDC: Centers for Disease Control; CECC: Central Epidemic Command Center; MHW: Ministry of Health and Welfare; SPSS: Statistical Package for Social Science; BSRS-5: Brief Symptom Rating Scale.

\section{Declarations}

\section{Ethics approval and consent to participate}

This study was approved by the Taiwan Institutional Review Board prior to its inception (TCHIRB-10906004-E). The content of our research questionnaire meets the conditions for exemption from written informed consent the research is the lowest risk, and the possible risk to research object does not exceed those who have not participated in the research. It cannot be carried out without the research object's prior consent, and does not affect the rights and interests of the research object. Our content of this online questionnaire does not involve personal information. If the personnel of the group quarantine centers connected to the online questionnaire, they will first be asked to check whether they agree to answer the question, and only who answer agree can enter the questionnaire to participate in our study.

\section{Consent for publication}

Not applicable.

\section{Availability of data and materials}

Data sharing is not applicable to this article as no datasets were generated or analysed during the current study.

\section{Competing interests}

The authors declare that they have no competing interest.

\section{Funding}

This research did not receive any specific grant from funding agencies in the public, commercial or not-for-profit sectors.

\section{Authors' contributions}

YF and TC developed the research structure and design the study methods. SN, SY Chen and SY Chan performed the study procedures. SY Chen completes statistical data analysis. RC and SJ were involved in planning and supervised the work. YF and TC processed the study written content, performed the analysis, and drafted the manuscript. YF aided in interpreting the results and worked on the manuscript. All authors read and approved the final manuscript. 


\section{Acknowledgements}

We very thank Professor Ming-Been Lee generously agreed to let us use the five-item Brief-Symptom Rating Scale (BSRS-5) scale, and also thanks Wallace Academic Editing for assisting in correcting of English writing grammar.

\section{References}

1. Liu Y, Gayle AA, Wilder-Smith A, Rocklöv J. The reproductive number of COVID-19 is higher compared to SARS coronavirus. J Travel Med. 2020; 27(2):taaa021. https://doi.org/10.1093/jtm/taaa021

2. Zheng YY, Ma YT, Zhang JY, Xie X. COVID-19 and the cardiovascular system.Nat Rev Cardiol. 2020; 17(5): 259-6https://doi.org/10.1038/s41569-0200360-5

3. Acter T, Uddin N, Das J, Akhter A, Choudhury TR, Kim S. Evolution of severe acute respiratory syndrome coronavirus 2 (SARS-CoV-2) as coronavirus disease 2019 (COVID-19) pandemic: A global health emergency. Sci Total Environ. 2020; 730: 138996. https://doi.org/10.1016/j.scitotenv.2020.138996

4. Severe Pneumonia with Novel Pathogens in Taiwan. Wikipedia. https://zh.wikipedia.org/wiki/2019\%E5\%86\%A0\%E7\%8B\%80\%E7\%97\%85\%E6\%AF\%92\%E7\%97\%85\%E8\%87\%BA\%E7\%81\%A3\%E7\%96\%AB\%E6\%83\%85. Accessed May 82020.

5. Severe Pneumonia with Novel Pathogens.Taiwan Centers for Disease Control. https://www.cdc.gov. tw/ Disease/Sublndex/N6XvFa1YP9CXY dB0kNSA9A. Accessed 15 Jan 2020.

6. Total Count of Severe Pneumonia with Novel Pathogens [Internet]. Taiwan Centers for Disease Control. https://www.cdc.gov.tw/. Accessed May 8 2020.

7. Work guidelines of group quarantine station for Severe Pneumonia with Novel Pathogens. Taiwan Centers for Disease Control. https://www.cdc.gov.tw/. Accessed 12 Feb 2020.

8. Tam CW, Pang EP, Lam LC, Chiu HF. Severe acute respiratory syndrome (SARS) in Hong Kong in 2003: stress and psychological impact among frontline healthcare workers. Psychol Med. 2004; 34(7): 1197-204. https://doi.org/10.1017/S0033291704002247

9. Maunder RG, Lancee WJ, Rourke S, Hunter JJ, Goldbloom D, Balderson K, et al. Factors associated with the psychological impact of severe acute respiratory syndrome on nurses and other hospital workers in Toronto. Psychol Med. 2004; 66(6): 938-

42.https://doi.org/10.1097/01.psy.0000145673.84698.18

10. Lancee WJ, Maunder RG, Goldbloom DS. Prevalence of psychiatric disorders among Toronto hospital workers one to two years after the SARS outbreak. Psychiatr Serv. 2008;59(1): 91-5. https://ps.psychiatryonline.org/doi/full/10.1176/ps.2008.59.1.91

11. Nickell LA, Crighton EJ, Tracy CS, Al-Enazy H, Bolaji Y, Hanjrah S, et al. Psychosocial effects of SARS on hospital personnel: survey of a large tertiary care institution. Cmaj. 2004; 170(5): 793-8.https://doi.org/10.1503/cmaj.1031077

12. Lee MB, Liao SC, Lee YJ, Wu CH, Tseng MC, Gau SF, et al. Development and verification of validity and reliability of a short screening instrument to identify psychiatric morbidity. J Formos Med Assoc. 2003; 102(10): 687-94. https://www.nejm.org/doi/full/10.1056/NEJMc2001468

13. Li Q, Guan X, Wu P, Wang X, Zhou L, Tong Y, et al. Early transmission dynamics in Wuhan, China, of novel coronavirus-infected pneumonia. N Engl J Med. 2020; 382: 1199-207.https://www.nejm.org/doi/full/10.1056/NEJMOa2001316

14. Rothe C, Schunk M, Sothmann P, Bretzel G, Froeschl G,Wallrauch C, et al. Transmission of 2019-nCoV infection from an asymptomatic contact in Germany. N Engl J Med. 2020; 382(10): 970-1. https://www.nejm.org/doi/full/10.1056/NEJMc2001468

15. Feng MC, Wu HC, Lin HT, Lei L, Chao CL, Lu CM, et al. Exploring the stress, psychological distress, and stress-relief strategies of Taiwan nursing personnels facing the global outbreak of COVID-19. Hu Li Za Zhi. 2020; 67(3): 64-74. https://doi.org/6224/JN.202006_67(3).09

\section{Figures}


Five types of people were eligible to be quarantined :

$\diamond$ Type1:The travelers subject to mandatory group quarantine after entering the country.

$\diamond$ Type2: People who had been in frequent contad with those diagnosed with COVID -19 as well as

people who did not follow related regulations during home isolation.

\& Type3:The individuals who entered Taiwan from regions of outbreaks and did not adhere to related regulations during home quarantine.

$\rightarrow$ Type4: The individuals for whom no home isolation or home quarantine site was available after

coordination by local governments.

$\diamond$ Type5 Those who have been approved by the Central Epidemic Command Center for severe pneumonia with novel pathogens.

$\diamond$ Health group personnel handle the followingitems:

- Group quarantine notice and notice of right to arraignments

- Designated quarantine locations

- Traffic arrangements for quarantine persons to designated quarantine locations (Type 2, Type 3 and Type 4)

\& Safety group personnel handle the followingtems:

- Traffic arrangements to designated quarantine locations (Type 1)

- To ensure the security of quarantine personnel to quarantinelocation

$\diamond$ Safety group(policemen and chauffeurs)

-Group quarantine access control management and personnel security.

-Picking up people for quarantine.

$\diamond$ Logistics group (logistics administrators and cleaners)

- A helping the quarantined subjects check in and check out.

- Ensuring an adequate stock of protective equipment.

- Performing environmental disinfection and deaning

$\diamond$ Health group (doctors, nurses, infection control personnel, and medical administrator

-Caring about the health of quarantined subjects by telephone.

- Performing daily symptom estimations for the quarantined subjects.

- Arranging medical treatment.

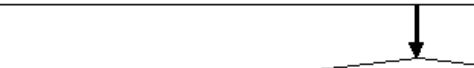

$=$

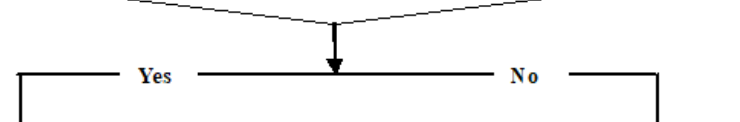

$\checkmark$ The health group informs the health bureau of the urisdiction, and the health bureau will arrange medical treatment.

$\checkmark$ A fter the doctor's assessment, there is no need to

stay in the hospital for observation. The people

must return to continue the quarantine and complete

14-day quarantine.

\section{Figure 1}

Standard operating procedures of group quarantine station [7]

\section{Supplementary Files}

This is a list of supplementary files associated with this preprint. Click to download.

- SupplementaryQuestionnaireBSRS5.docx 